\title{
Harnessing of Chemically Modified Rice Straw Plant Waste as Unique Adsorbent for Reducing Organic and Inorganic Pollutants
}

\author{
Khaled Mohamed Mostafa ${ }^{1^{*}}$, Abdul Rahim Samarkandy², Azza Awad El-Sanabary ${ }^{3,4}$ \\ ${ }^{1}$ National Institute for Standards, Textile and Chemical Meteorology Division, El-Haram, Egypt \\ ${ }^{2}$ Faculty of Science, Chemistry Department, King Abdul Aziz University, Jeddah, KSA \\ ${ }^{3}$ Faculty of Science for Girls, King Abdul Aziz University, Jeddah, KSA \\ ${ }^{4}$ Polymers and Pigment Department, National Research Center, Cairo, Egypt \\ Email: *kh_mostafa@hotmail.com
}

Received February 15, 2012; revised March 29, 2012; accepted April 9, 2012

\begin{abstract}
Conversion of rice straw (RS) as one of agricultural plant wastes (about $45 \%$ of the volume of rice production) to valuable industrial product was achieved, by grafting different amounts of dimethylaminoethyl methacrylate (DMAEM) on it using potassium permanganate/nitric acid redox system. This was done to obtain six levels of poly (DMAEM)—rice straw graft copolymers (PDMAEMRS) having different graft yields (expressed as N\%) with increasing order and designated as (PDMAEMRS 1 to PDMAEMRS 6). The latter copolymers were dispersed in aqueous solution of heavy metal ions $\mathrm{Cu}$ (II) ions and filtered to form rice straw co-polymer-metal ions complex. Different factors affecting the heavy metal ions removal such as $\mathrm{pH}$, extent of grafting, treatment time and rice straw dose were studied in detail. It was found from the obtained results that; the residual metal ions removal from their aqueous solutions increased with 1) Increasing the extent of grafting of PDMAEMRS i.e. from PDMAEMRS 1 to PDMAEMRS 6; 2) Increasing the pH of the metal ions solution complex from 1 to 8; 3) Increasing the rice straw dosage from 0.50 to $2.0 \mathrm{~g}$, then leveled off thereafter; 4) Increasing the time of the reaction up to 20 minute then leveled off after that. On the other hand, $\mathrm{Pb}$ (II), Cd (II) and Hg (II) ions were also removed from their solutions with different extent. Furthermore, the prepared copolymer could be recovered by washing the metal ions from the complex with weak acid $1 \mathrm{~N} \mathrm{HNO}_{3}(\mathrm{pH} 2)$ and the metal-binding activity of the rice straw was slightly reduced by this process. Finally, the ability of PDMAEMRS to remove three types of acid dyes from their solutions was also reported.
\end{abstract}

Keywords: Rice Straw; Pulping; Bleaching; Dimethylaminoethyl Methacrylate; Grafted Rice Straw; Heavy Metal Ions Removal; Acid Dyes

\section{Introduction}

Heavy metals and organic pollutants have been successively released into the environment due to rapid industrialization and have created major worldwide concerns. Cadmium, zinc, copper, nickel, lead, mercury and chromium and dyes are often detected in industrial waste waters, which originate from metal plating, mining activities, smelting, battery manufacture, tanneries, petroleum refining, paint manufacture, pesticides, pigment manufacture, printing, textiles and photographic industries [1,2]. Unlike organic wastes, heavy metals are non-biodegradable and they can be accumulated in living tissues, causing various diseases and disorders; therefore they must be removed before discharge. Research interest into the

\footnotetext{
${ }^{*}$ Corresponding author.
}

production of cheaper adsorbents to replace costly wastewater treatment methods such as chemical precipitation, ion-exchange, electro flotation, membrane separation, reserve osmosis, electro dialysis and solvent extraction are attracting attention of scientists [3]. Adsorption is one of the physico-chemical treatment process found to be effective in removing heavy metals from aqueous solutions. Adsorbent can be considered as cheap or low cost if it is abundant in nature, requires little processing and is a by-product of waste material from waste industry [4]. Plant wastes are inexpensive as they have no or very low economic value. Most of adsorption studies have been focused on unwanted plant wastes such as papaya wood [5], maize leaf [6], teak leaf powder [7], rubber leaf powder [8,9], lalang leaf powder [10], coriandrum sativum [11], peanut hull pellets [12], sago waste [13], tree 
fern [14] and rise husk ash and neem bark [15], bark and sawdust [16], maize cobs [17], and wheat barn [18]. Some of the advantageous of using plant wastes for waste water treatment include simple technique, requires little processing, good adsorption capacity, selective adsorption of heavy metal ions, low cost, free availability and easy regeneration. However, the application of untreated plant wastes as adsorption can also bring several problems such as low adsorption capacity, high Chemical Oxygen Demand (COD) and Biological Oxygen Demand (BOD) as well as Total Organic Carbon (TOC) due to release of soluble organic compounds contained in the plant materials $[19,20]$. The increase in COD BOD and TOC can cause depletion of oxygen content in water and can threaten the aquatic life. Therefore, plant wastes need to be modified or treated before being applied for the decontamination of heavy metals.

In our case here, rice straw represents about $45 \%$ of the volume of rice production, producing the largest quantity of rice crop residue. As rice straw is a marginal feed compared to other cereal grain straw and a problematic fuel source due to high ash generation, exploring more viable options to utilize rice straw is pressing, particularly as an environment concern [21]. So, our research team directed their efforts in this study to convert rice straw as a waste material into valuable industrial products via synthesize poly (DMAEM) - rice straw pulp graft copolymer (PDMAEMRS) having different graft yields expressed as nitrogen (\%) (a point that has not been reported). The latter were prepared by grafting different amount of monomer onto rice straw using potassium permanganate/nitric acid system toward systematic study on $\mathrm{Cu}^{2+}$ ions removal from their solutions in addition to, $\mathrm{Pb}^{2+}, \mathrm{Cd}^{2+}$, and $\mathrm{Hg}^{2+}$. For this purpose, various factors affecting the adsorption, such as $\mathrm{pH}$, treatment time, extent of grafting, rice straw dose and recovery of rice straw were studied in detail. In addition, the ability of PDMAEMRS to remove acid dyes from their solutions was also reported.

\section{Material and Methods}

\subsection{Materials}

Rice straw used in this study was collected from 2010 harvest time from Belqas, El-Dakahlya governorate, Egypt. Dimethylaminoethyl methacrylate stabilized with $0.01 \%$ hydroquinone was freshly distilled at $75^{\circ} \mathrm{C}$ and pressure of $100 \mathrm{~mm} \mathrm{Hg}$. It was stored at $-10^{\circ} \mathrm{C}$ until used. Sodium chloride, potassium permanganate, sulphuric, hydrochloric and nitric acids, sodium hydroxide, ethanol, anthraquinone, $\mathrm{H}_{2} \mathrm{O}_{2}, \mathrm{CuSO}_{4} \cdot 5 \mathrm{H}_{2} \mathrm{O}, \mathrm{Pb}\left(\mathrm{CH}_{3} \mathrm{CO}_{2}\right)_{2} \cdot 3 \mathrm{H}_{2} \mathrm{O}$, $\mathrm{Hg}\left(\mathrm{CH}_{3} \mathrm{CO}_{2}\right)_{2}$, and $\mathrm{CdSO}_{4}$ (check with other salt below) were reagent grade chemicals.

\subsection{Pretreatment of Rice Straw}

\subsubsection{Physical Tool}

This was done to remove dirt and aqueous soluble substances via soaking rice straw into a detergent solution for $60 \mathrm{~min}$, followed by extensive washing 3 - 4 times with tap water for $1 \mathrm{~h}$ and finally with distilled water, and squeezed. The samples were then dried in a drying oven at $40^{\circ} \mathrm{C}$ for $8 \mathrm{~h}$ then left to dry in air for ONE WEEK.

\subsubsection{Chemical Tool}

\subsubsection{Alkaline Pulping}

Rice straw was added to ethanol (50\%) using a material to liquor ratio of $1: 10$. Sodium hydroxide $(2.5 \%)$ and anthraquinone $(0.1 \%)$ were then added to the mixture. The mixture was refluxed at temperature of $85^{\circ} \mathrm{C}$ for $3 \mathrm{~h}$. The pulp was extracted and soaked in $1 \mathrm{~L}$ cold ethanol (50\%) overnight. After this the pulp was washed with cold tap water to complete purity and air dried.

\subsubsection{Bleaching}

Rice straw was bleached using $4 \% \mathrm{H}_{2} \mathrm{O}_{2}$ in a single stage process at $105^{\circ} \mathrm{C}$ for 1 hour [22].

\subsection{Preparation of Poly (Dimethylaminoethyl Methacrylate)_-Rice Straw Pulp Graft Copolymer Having Different Graft Yields}

Six levels of poly (DMAEM)—rice straw pulp graft copolymers with different graft yields (expressed as N\%), used as adsorbents for $\left(\mathrm{Cu}^{2+}, \mathrm{Pb}^{2+}, \mathrm{Cd}^{2+}\right.$ and $\left.\mathrm{Hg}^{2+}\right)$ ions in this study, were synthesized by keeping all the grafting reaction conditions constant and varying only the monomer concentration. Details of the conditions used as well as characterizations of PDMAEMRS are given in Table 1.

Unless other wise indicated, the graft polymerization reaction was carried out in $100 \mathrm{ml}$ stoppered flasks containing an aqueous solution of monomer (25\%, $50 \%, 75 \%$, $100 \%, 125 \%$ and $150 \%$ based on weight of substrate i.e. rice straw pulp). The flasks were stoppered and placed in a thermostatic water bath until the required temperature was reached. Nitrogen gas was purged through this solution to remove the dissolved oxygen. The rice straw (10 g), (40 meq/L) $\mathrm{KMnO}_{4}$ and $80 \mathrm{meq} / \mathrm{L}$ nitic acid were then added and the reaction mixture was mixed thoroughly. The total volume was adjusted to be $500 \mathrm{ml}$. The contents were shaken occasionally during polymerization for $3 \mathrm{~h}$ at $55^{\circ} \mathrm{C}$. After the desired reaction time, the flask contents were poured over $500 \mathrm{ml}$ of ethanol where a precipitate was formed, which consisted of rice straw pulp graft copolymer and the homopolymer. The homopolymer poly (dimethylaminoethyl methacrylate) was 
Table 1. Preparation of poly (DMAEM)—rice straw pulp graft copolymer having different graft yields (expressed as nitrogen \%) as well as their main characteristics.

\begin{tabular}{cccc}
\hline Rice straw type & $\begin{array}{c}\text { Dimethylaminoethyl } \\
\text { methacrylate } \\
\text { concentration (based on } \\
\text { weight of substrate) }\end{array}$ & Nitrogen \% & $\begin{array}{c}\text { Apparent } \\
\text { viscosity } \\
\text { (m.pa.s) }\end{array}$ \\
\hline Blank & 0 & 0.05 & 255 \\
PDMAEMRS 1 & 25 & 0.65 & 270 \\
PDMAEMRS 2 & 50 & 1.35 & 281 \\
PDMAEMRS 3 & 75 & 1.87 & 290 \\
PDMAEMRS 4 & 100 & 2.31 & 305 \\
PDMAEMRS 5 & 125 & 2.55 & 320 \\
PDMAEMRS 6 & 150 & 2.95 & 330 \\
\hline
\end{tabular}

Rice straw pulp, $10 \mathrm{~g}$; $\left[\mathrm{KMnO}_{4}\right.$ ], 40 meq/L; [nitric acid], 80 meq/l, material to liquor ratio, 1:50; Time, $3 \mathrm{hr}$; and temperature, $55^{\circ} \mathrm{C}$; N.B.; Blank: Rice straw prior to grafting: PDMAEMR S 1: Poly (DMAEM) - rice straw graft copolymer with 0.65 N\%; PDMAEMRS 2: Poly (DMAEM) - rice straw graft copolymer with $1.35 \mathrm{~N} \%$; PDMAEMRS 3: Poly (DMAEM)—rice straw graft copolymer 1.87 N\%; PDMAEMRS 4: Poly (DMAEM)—rice straw graft copolymer with $2.31 \mathrm{~N} \%$; PDMAEMRS 5: Poly (DMAEM)—rice straw graft copolymer with 2.55 N\%; PDMAEMRS 6: Poly (DMAEM)—rice straw starch graft copolymer with $2.95 \mathrm{~N} \%$.

removed from the reaction mixture by washing the precipitate five times with $400 \mathrm{ml}$ of water/ethanol mixture (30:70, v/v) for $15 \mathrm{~min}$. at room temperature on magnetic stirrer, filtered and finally dried in an electric oven at $60^{\circ} \mathrm{C}$ for $2 \mathrm{~h}$. It was found experimentally that washing five times with a mixture of water/ethanol mixture (30/70, $\mathrm{v} / \mathrm{v}$ ) is quite enough for complete removal of homopolymer in physical mixture of rice straw/poly (Dimethylaminoethyl methacrylate), by estimating nitrogen \% of the mixture after each wash until constant value.

\subsection{Determination of Nitrogen}

It was estimated by a well known kejeldhal method [23].

\subsection{Proof of Grafting}

This was done via measuring the nitrogen \% of the grafted samples three times for each sample, as well as their standard deviation. On other word, both the nitrogen \% and standard deviation were taken as an evidence or confirmation of grafting of dimethylaminoethyl methacrylate onto rice straw pulp that is free from nitrogen groups as a starting substrate.

\subsection{Heavy Metal Ions Removal}

An aqueous solution of copper ions (Cu 203 ppm) was prepared by dissolving cupric sulfate $\left(\mathrm{CuSO}_{4} \cdot 5 \mathrm{H}_{2} \mathrm{O}, 0.8\right.$ g) in distilled water 1 litter. Poly (DMAEM)-rice straw pulp graft copolymer $(0.25-4.00 \mathrm{~g})$ was then added to the copper solution $(100 \mathrm{ml})$, and the dispersion was stirred for $45 \mathrm{~min}$ at room temperature $\left(26^{\circ} \mathrm{C} \pm 0.5^{\circ} \mathrm{C}\right)$ to form a complex with the metal ions. The grafted rice straw pulp-heavy metal ions complex was then removed by filtration and the filtrate was used for the residual metal analysis. On the other hand, to evaluate the removal effect of other metal ions, Pb (203 ppm), Cd (194 ppm) and $\mathrm{Hg}$ (208 ppm) solutions were prepared by dissolving lead acetate $\left(\mathrm{Pb}\left(\mathrm{CH}_{3} \mathrm{CO}_{2}\right) 2.3 \mathrm{H}_{2} \mathrm{O}, 0.374 \mathrm{~g}\right)$, mercuric acetate $\left(\mathrm{Hg}\left(\mathrm{CH}_{3} \mathrm{CO}_{2}\right)_{2}, 0.33 \mathrm{~g}\right)$ and cadmium sulfate $\left(\mathrm{CdSO}_{4}, 0.359 \mathrm{~g}\right)$ in distilled water $(1 \mathrm{~L})$ respectively.

After the metal solution was treated with the grafted rice straw pulp, residual metal ion content in the filtrate was measured by a colorimetric method using Atomic Absorption Spectrophotometer.

\subsection{Recovery of the Prepared Copolymer}

Poly (DMAEM) — rice straw pulp graft copolymer (1 g) at $\mathrm{pH} 8$ used to remove copper ions was redispersed in distilled water $(40 \mathrm{ml})$, and the dispersion was adjusted to $\mathrm{pH} 2$ by adding $1 \mathrm{~N} \mathrm{HNO}_{3}$ solution. After stirring for $10 \mathrm{~min}$, the dispersion was filtered. The rice straw pulp residue was washed with water and readjusted to $\mathrm{pH} 8$ with $1 \mathrm{~N} \mathrm{NaOH}$ and dried at $40^{\circ} \mathrm{C}$ overnight. The degree of $\mathrm{Cu}$ removal using the recovered rice straw was measured and compared with the unrecovered one.

\subsection{Dyes Removal}

1.0 g of Poly (DMAEM)_rice straw pulp graft copolymer and $100 \mathrm{ml}$ of an aqueous solution of dye $(100 \mathrm{mg} / \mathrm{L})$ were placed in 125 glass-stoppered flasks without $\mathrm{pH}$ adjustment and automatically shaken for $24 \mathrm{~h}$ at room temperature $\left(26^{\circ} \mathrm{C} \pm 1^{\circ} \mathrm{C}\right)$. The flasks content were filtered and the concentration of the dye in the filtrate was measured using a Shimadzu UV/visible Spectrophotometer at maximum wavelength of each dye. The sorption capacity was then calculated and expressed in percentage uptake ( $\mathrm{R}$ in \%), which represents the ratio between the amount-adsorbed dye and the starting amount dye.

$$
\mathrm{R} \%=\frac{\text { Amount of dye adsorbed }}{\text { Total amount of dye }} \times 100
$$

The Acid Orange 12 (AO120), Acid Red 14 (AR14) and Acid Orange 7 (AO7) dyes (Aldrich) were used for dye removal on the prepared copolymer.

\section{Results and Discussion}

\subsection{Effect of $\mathbf{p H}$}

Figure 1 represents the effect of changing $\mathrm{pH}$ of poly (DMAEM) - rice straw pulp graft copolymer (expressed N\%) on the $\mathrm{Cu}$ removal from its solution at fixed nitrogen \% i.e. 2.95. It is seen Figure 1 that, residual $\mathrm{Cu}$ ion concentration in the filtrate decreased when $\mathrm{pH}$ increased 


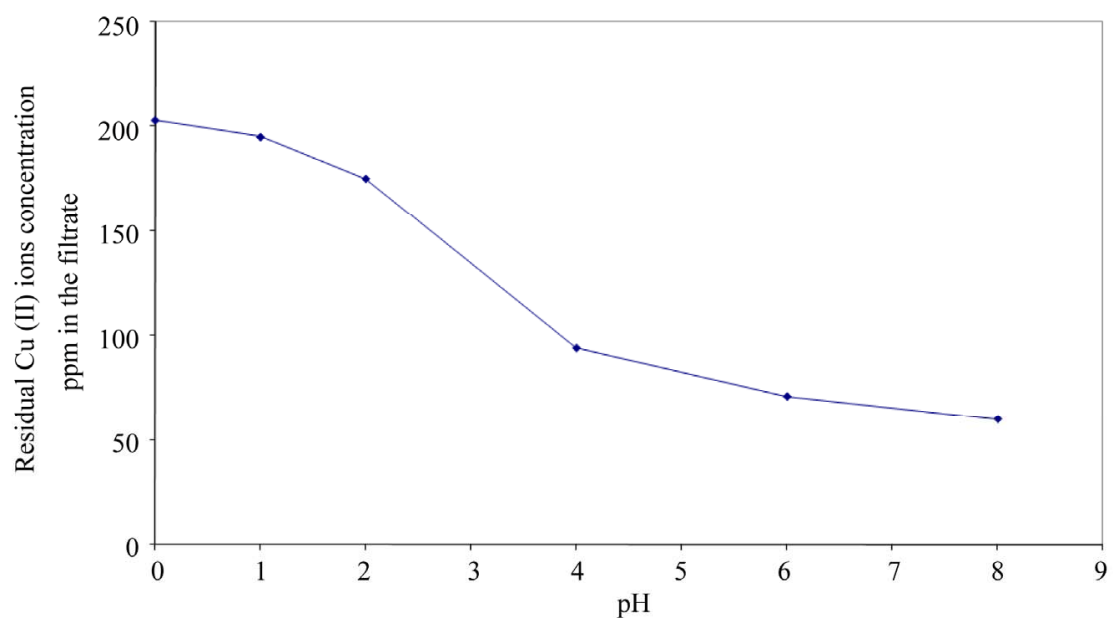

Figure 1. The relation between residual $\mathrm{Cu}$ ion content and $\mathrm{pH}$ in the metal-copolymer complex solution; Reaction conditions: PDMAEMRS, 2 g; Initial Cu conc., 203 ppm; Total volume, $100 \mathrm{ml}$; N\%, 2.95; Time, $20 \mathrm{~min}$; Temperature, $26^{\circ} \mathrm{C} \pm 1^{\circ} \mathrm{C}$.

from 1 to 8 . This is in accordance with the results published by $\mathrm{Xu}$ et al., 2005 [24], Gue et al., 2005 [25], Kweon et al., 2001 [26] and Zhang et al., 2000 [27].

Due to the protonation and deprotonation of the tertiary amine groups on the surface of rice straw pulp graft copolymer, its adsorption behavior for metal ions is influenced by the $\mathrm{pH}$ values as shown in Figure 1. The examined test were limited to the $\mathrm{pH}$ range from 1 - 8 because of the known precipitate of $\mathrm{Cu}(\mathrm{OH})_{2}$ in alkaline medium.

For more detail, at pH 8 the residual metal ion content decreases from 203 ppm as a starting concentration in absence of rice straw pulp copolymer to $65 \mathrm{ppm}$ in presence of it. Further more, the residual metal ion concentration increases by decreasing the $\mathrm{pH}$ from 6 to 4 to 2 and finally to 1 but with lesser extent. The decrement in the residual metal ion concentration follows the order: pH $8>$ pH $6>$ pH $4>$ pH $2>1$.

When the rice straw pulp $\mathrm{pH}$ was 6 or 4 , the residual $\mathrm{Cu}$ content in the filtrate decreased to $92 \mathrm{ppm}$ or 101 ppm respectively. While at lower $\mathrm{pH}$ i.e. 2 and 1 the rice straw pulp was no longer effective in removing $\mathrm{Cu}$ from the solution (i.e. the rice straw pulp did not show $\mathrm{Cu}$ binding activity i.e. not amenable. This can be explained by the fact that at lower $\mathrm{pH}$ value most of tertiary amine groups in the copolymer are protonated. Then cationic repulsion can occur between metal ion species and protonated grafted chains. The opposite hold true at higher $\mathrm{pH}$ values (6 to 8). On the other word, most of tertiary amine groups in the copolymer are less protonated which lead to strong complexation between the copolymer and metal ion in question [28].

\subsection{Effect of Extent of Grafting on Metal Removal}

Figure 2 declares the effect of changing the extent of grafting (expressed as N\%) of poly (DMAEM) - rice straw pulp graft copolymer (expressed as $\mathrm{N} \%$ ) on the $\mathrm{Cu}$ removal from its solution at $\mathrm{pH}$ 8. It is seen Figure 2 that, for $\mathrm{Cu}$ removal, residual metal ion concentration in the solution decreased when nitrogen \% of poly (DMAEM) - grafted rice straw pulp copolymer increased. So, by increasing the nitrogen \% of the copolymer from 0.65 to 2.95 would lead to a decrease in residual metal ion concentration from 203 to 60 ppm as shown before at pH 8 . This indicates that the metal ions in the solution interact more likely with higher extent with the tertiary aminated groups of poly (DMAEM) - rice straw pulp graft copolymer, which reflect the role of extent or degree of grafting on the heavy metal ions binding activity or removal. The latter was not reported for our knowledge in the literature until now.

\subsection{Effect of Treatment Time on the Metal Removal}

Figure 3 shows the effect of treatment time on the removal of $\mathrm{Cu}$ ions with poly (DMAEM)-rice straw pulp graft copolymer at optimum conditions observed before.

It is seen Figure $\mathbf{3}$ that, the $\mathrm{Cu}$ removal was completed within the first $20 \mathrm{~min}$. induction period, which indicate that the copper ions rapidly form chelates or interaction with the tertiary amine groups of the cross linked rice straw pulp graft copolymer. This rapid interaction will be beneficial for practical application, i.e. the latter copolymer could be used as a filtering resin for a short period of treatment of wastewater during filtration.

\subsection{Effect of PDMAEMRS Dose Used}

When the dose of poly (DMAEM) — rice straw pulp graft copolymer added to the copper solution (203 ppm $\mathrm{Cu}$ ) was increased from $0.5 \mathrm{~g}$ to $4.0 \mathrm{~g}$, the residual $\mathrm{Cu}$ content 


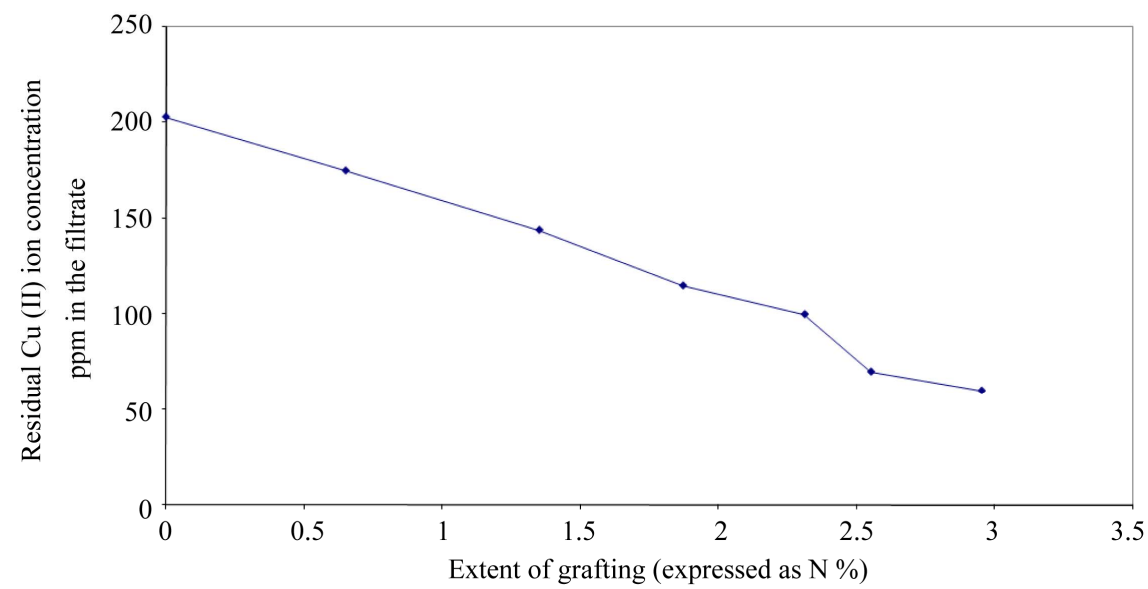

Figure 2. Effect of varying the extent of grafting (expressed as $\mathrm{N} \%$ ) on the residual $\mathrm{Cu}$ ion in the metal-copolymer complex solution; Reaction conditions: PDMAEMRS, 2 g; Initial Cu conc., 203 ppm; Total volume, 100 ml; pH, 8; Time, 20 min; Temperature, $26^{\circ} \mathrm{C} \pm 1^{\circ} \mathrm{C}$.

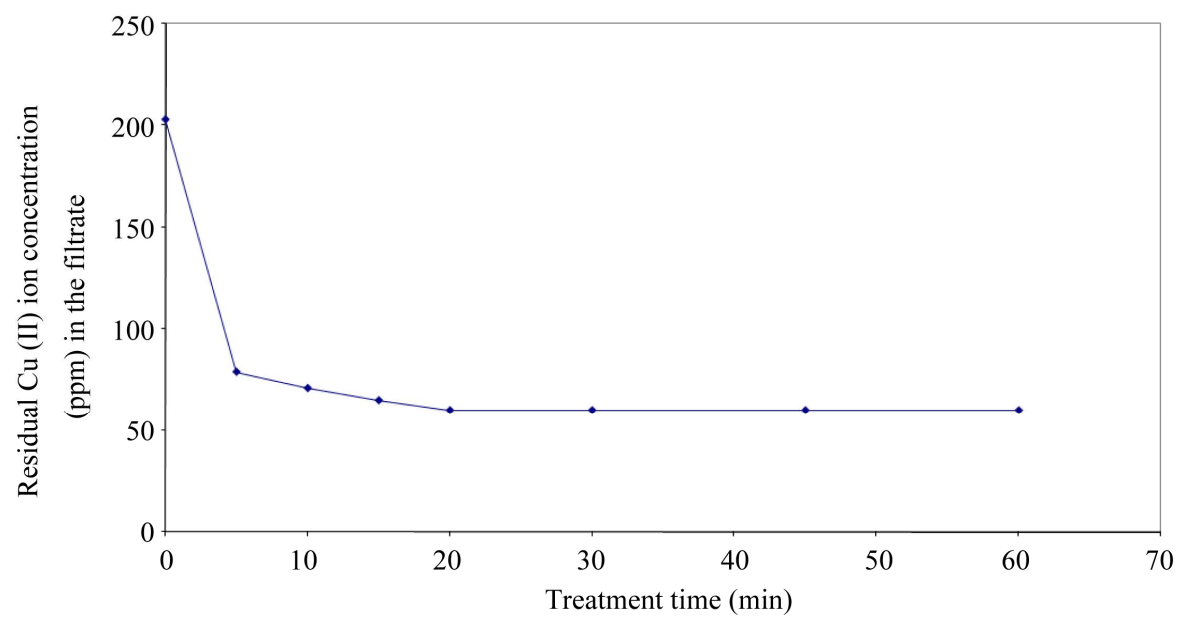

Figure 3. Effect of treatment time on the residual $\mathrm{Cu}$ ions removal using PDMAEMRS; Reaction conditions: PDMAEMRS, 2 g; Initial Cu conc., 203 ppm; Total volume, $100 \mathrm{ml}$; $\mathrm{N} \%$, 2.95; $\mathrm{pH}, 8$; Temperature, $26^{\circ} \mathrm{C} \pm 1^{\circ} \mathrm{C}$.

in the filtrate decreased gradually (Figure 4). At 2.95 nitrogen \%, the copper ions in the solution were almost completely removed with $2.0 \mathrm{~g}$ rice straw pulp addition based on solution volume, and then leveled off after that. This corresponds to an increase in copolymers active sites as well as saturation occurred at $2.0 \mathrm{~g}$ at which further increase in rice straw pulp dosage had little or no effect on metal removal. A point should be useful for establishing the optimum economical dose of PDMAEMRS in metal removal.

\subsection{Removal of Other Heavy Metal Ions}

Six levels of poly (DMAEM) - rice straw pulp graft copolymers their graft yields ranged from $(0.65-2.95$ nitrogen \%) were used for removing different heavy metal ions from their solutions at a similar concentration (about $200 \mathrm{ppm}$ ). The different heavy metal ions used were $\mathrm{Pb}^{2+}$, $\mathrm{Cd}^{2+}$ and $\mathrm{Hg}^{2+}$. The obtained results are set out in Figure
5. Details of the conditions used are set out elsewhere.

It is seen from Figure $\mathbf{5}$ that, the residual amount of heavy metal ions removed is governed by the \% nitrogen (Graft yield) as well as the nature of metal ion used. So, when the nitrogen \% increased from 0.65 - 2.95, the residual removal of heavy metal increased irrespective of the nature of metal ion used. It is also seen that, the synthesized poly (DMAEM) — rice straw pulp graft copolymers are more effective in removing $\mathrm{Hg}^{2+}$ than all other metal ions in question and follow the order:

$$
\mathrm{Hg}^{2+}>\mathrm{Cd}^{2+}>\mathrm{Pb}^{2+}
$$

This can be explained in terms of, the differences between the metal ions in questions with respect to; 1 ) relative atomic size; 2) ability for metal ion to interact with the polymer; 3) metal ion charge density and 4) reactivity of the metal ion. In addition, Khalil et al., 2000, [29] said that, $\mathrm{Hg}^{2+}$ acquires the highest sorption value amongst the variable studied metal ions used i.e. $\mathrm{Cu}^{2+}, \mathrm{Zn}^{2+}, \mathrm{Co}^{2+}$, 


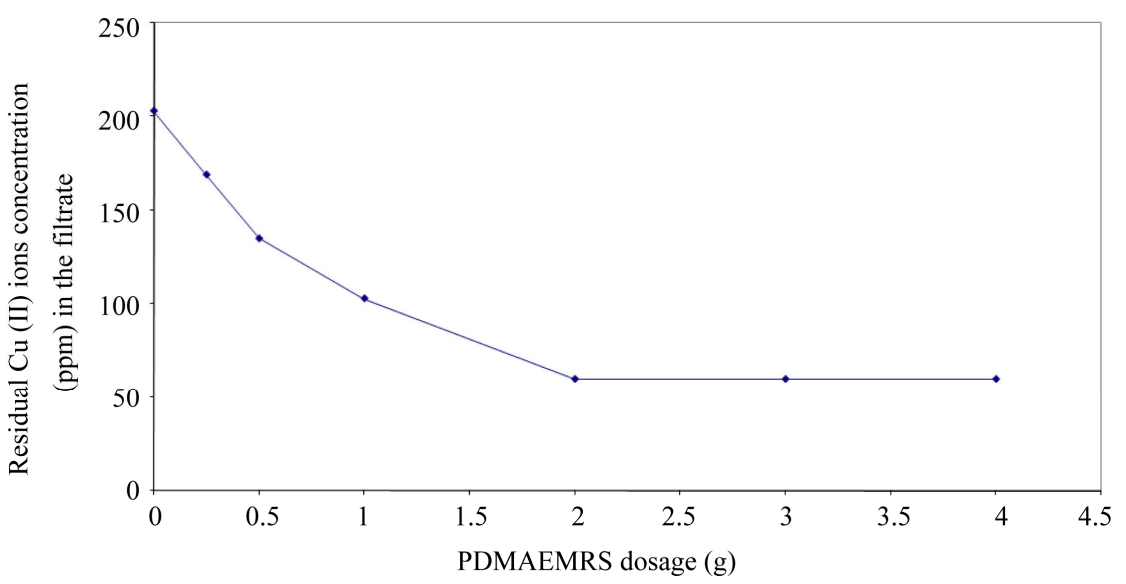

Figure 4. Effect of dosage of PDMAEMRS on the residual $\mathrm{Cu}$ ions concentration (ppm) removal from metal-copolymer complex solution; Reaction conditions: Initial Cu conc., 203 ppm; Total volume, 100 ml; N\%, 2.95; Time, pH 8, 20 min; Temperature, $26^{\circ} \mathrm{C} \pm 1^{\circ} \mathrm{C}$.

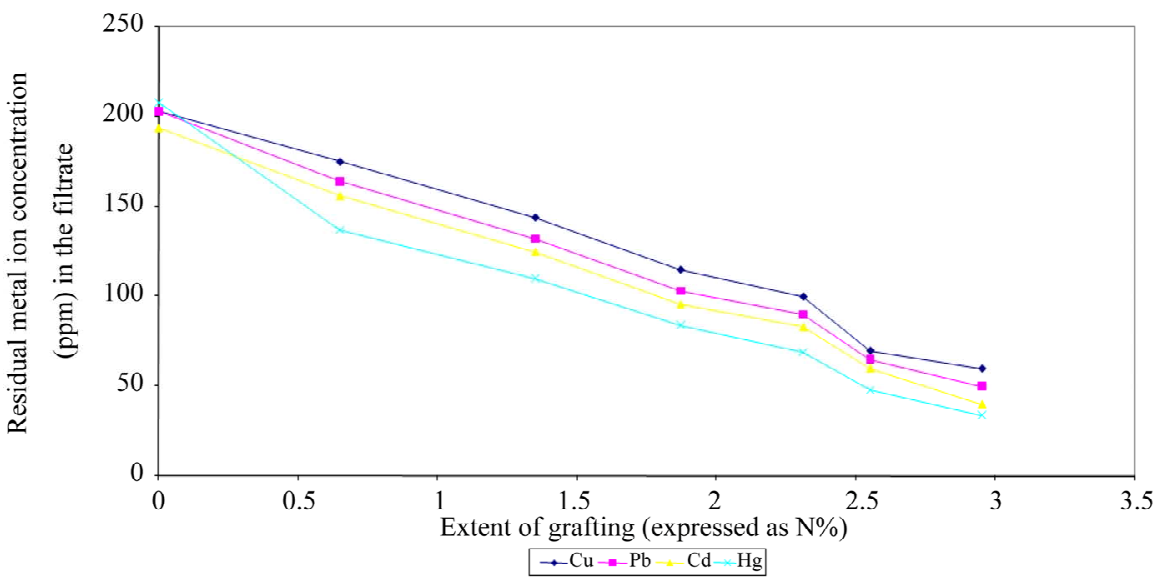

Figure 5. The relation between changing the extent of grafting (expressed as N\%) on the removal of different heavy metal ions in questions; Reaction conditions: PDMAEMRS, 2 g; Initial metal ion conc., about 202 ppm; Total volume, 100 ml; pH, 8; time, 20 min; Temperature, $26^{\circ} \mathrm{C} \pm 1^{\circ} \mathrm{C}$.

$\mathrm{Cd}^{2+}, \mathrm{Pb}^{2+}$; hence, $\mathrm{Hg}^{2+}$ will be used in comparing the sorption behavior of different legends. Furthermore, this is in accordance with the results also published by Khalil et al., 1999 [30] for the stability of various legends with nitrogen or oxygen as coordinating atoms for divalent transition metal ions.

\subsection{Recovery of Rice Straw Pulp}

Figure 6 shows the comparison of original (unrecovered) rice straw pulp and recovered one for poly (DMAEM)rice straw pulp graft copolymer under the same condition shown before in the experimental part on copper removal. It is seen from the figure that, the removal efficiency of the recovered rice straw pulp appears slightly less than that of fresh rice straw pulp. In case of $\mathrm{Cu}$ removal, the recovered rice straw pulp of 2.95 nitrogen \% $(\mathrm{pH} 8)$ reduced the copper ion content to $89 \mathrm{ppm}$ in comparison to $60 \mathrm{ppm}$ in comparison of unrecovered rice straw pulp.

\section{Dyes Removal}

The sorption capacity (dye uptake R\%) was investigated using three types of acid dyes namely Acid Orange 12 (AO12), Acid Red 14 (AR14) and Acid Orange 7 (AO7). The measurement of each dye must be at the maximum wave length of each dye which was as follows: 484, 514 and $484 \mathrm{~nm}$ respectively. This was done under the optimized experimental conditions as shown in the experimental part.

On the other hand, to evaluate the influence of the tertiary amine groups on the sorption capacity of anionic dye removal of the prepared copolymers, different tests were carried out using the six copolymers (PDMAEMRS 1 to PDMAEMRS 6) having different tertiary amine groups in addition to blank experiment of the polymer with zero nitrogen groups just for comparison. It seen from Figure 7 that, at any graft yield, the capacity of dyes removal follows the order: Acid Orange 7 (AO7) > 


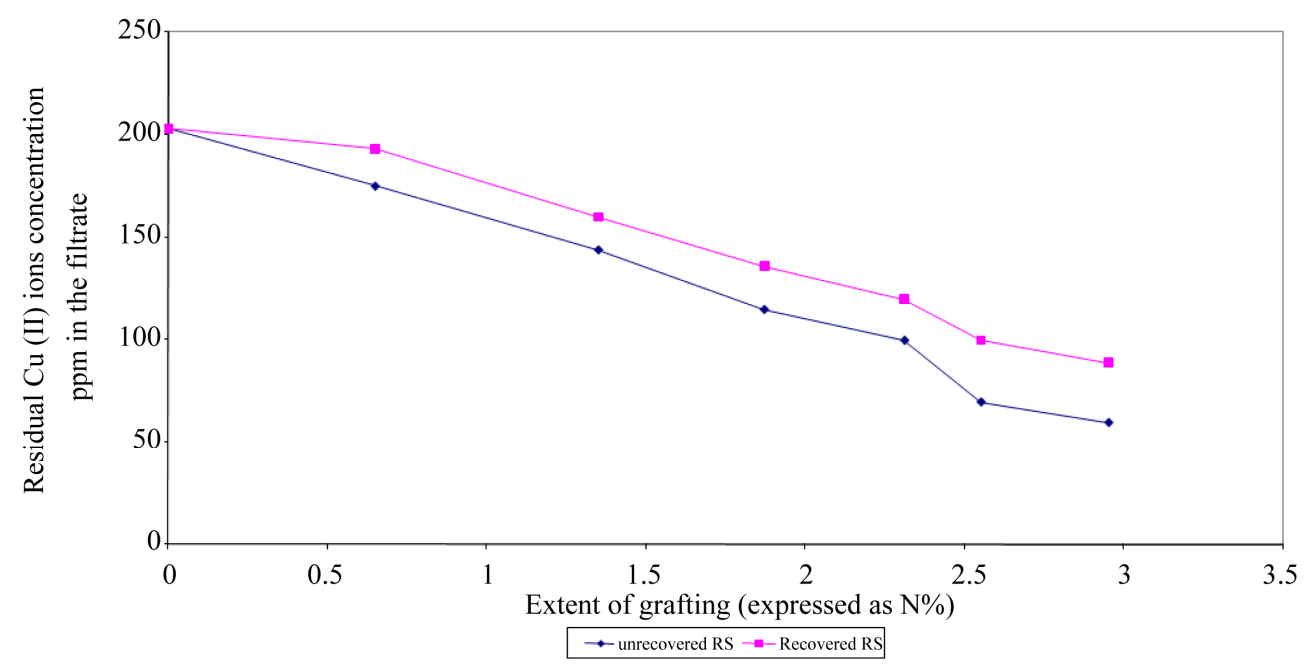

Figure 6. The difference between original unrecovered rice straw and recovered one of PDMAEMRS towards Cu ions removal from the metal-copolymer complex solution; Reaction conditions: PDMAEMRS, 2 g; Initial Cu conc., 203 ppm; Total volume, $100 \mathrm{ml}$; $\mathrm{pH}, 8$; Time, $20 \mathrm{~min}$; Temperature, $26^{\circ} \mathrm{C} \pm 1^{\circ} \mathrm{C}$.

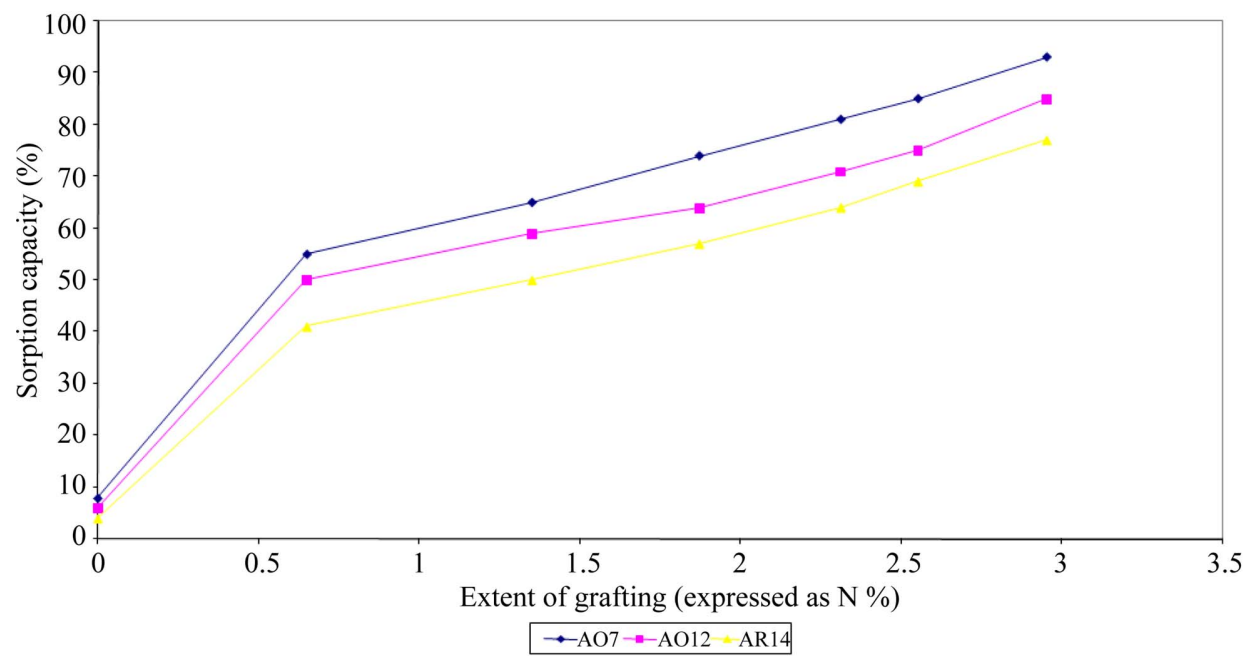

Figure 7. Relation between extent of grafting (expressed as N\%) and sorption capacity of dye adsorbed (R\%) on PDMAEMRS; Reaction conditions: PDMAEMRS, 0.5 g; Dye conc., $100 \mathrm{mg} / \mathrm{L}$; Total volume, $100 \mathrm{ml}$; Time, 24 hr; Temperature, $26^{\circ} \mathrm{C} \pm 1^{\circ} \mathrm{C}$.

Acid Orange 12 (AO12) > Acid Red 14 (AR14).

Furthermore, the amount of dye adsorbed for all dyes in questions increases by increasing the extent of grafting of the prepared copolymers. In other word, the acid dyes display the best interaction or sorption capacity with the copolymers in question containing higher tertiary amine groups (i.e. interaction between tertiary amine groups on the polymer and acid groups in the basic dyes). This was confirmed by the higher sorption capacities of the prepared copolymers that reach a maximum at 93 in case of acid Orange 7 (AO7), 85 for Acid Orange 12 (AO12) and 77 for Acid Red 14 (AR14) at higher nitrogen \% i.e. 2.95. Moreover, acidity, molecular size and stereochemistry of the dyes appeared to influence the amount of dye adsorbed on PDMAEMRS.

\section{Conclusion}

By grafting DMAEM onto rice straw pulp, the latter could become an active metal scavenger for heavy toxic divalent cations such as $\mathrm{Cu}, \mathrm{Pb}, \mathrm{Cd}$ and $\mathrm{Hg}$ ions contaminated in water as well as efficient acid dyes removal. At low nitrogen \% 0.65 of the copolymer, valuable amount of these metal ions (ppm) could be effectively removed from water by dispersing $2.0 \mathrm{~g}$ of the copolymer for (20 $\mathrm{min})$ at $\mathrm{pH} 8$ and subsequent filtering the rice straw pulp -metal complex. The rice straw could be regenerated by a weak acidic washing. For effective metal removal, the metal solution should not to be acidic. By raising the levels of grafting, metal scavenging activity of the copolymer could be increased up to the level required for 
industrial application. On the other hand, the latter prepared copolymers could be used also to remove acid dyes from their aqueous solutions and follows the order: Acid Orange 7 (AO7) $>$ Acid Orange 12 (AO12) $>$ Acid Red 14 (AR14).

\section{Acknowledgements}

The authors are greatly thankful to Deanship of scientific research, King Abdul Ariz University for its financial support of this work under the number MS/12/318.

\section{REFERENCES}

[1] K. Kadirvelu, K. Thamaraiselvi and C. Namasivayam, “A Removal of Heavy Metal from Industrial Waste Waters by Adsorption onto Activated Carbon Prepared from an Agricultural Solid Waste," Bioresource Technology, Vol. 76, No. 1, 2001, pp. 63-65. doi:10.1016/S0960-8524(00)00072-9

[2] C. J. Williamas, D. Aderhold and G. J. Edyvean, "Comparison between Biosorbents for the Removal of Metal Ions from Aqueous Solutions," Water Research, Vol. 32, No. 1, 1998, pp. 216-224. doi:10.1016/S0043-1354(97)00179-6

[3] C., Namasivayam and K. Ranganathan, "Removal of $\mathrm{Pb}$ (II), Cd (II), and Ni (II) and Mixture of Metal Ions by Adsorption onto Waste Fe (III)/Cr (III) hydroxide and Fixed Bed Studies,” Environmental Technology, Vol. 16, No. 9, 1995, pp. 851-860.

[4] S. E. Bailey, T. J. Olin, R. M. Bricka and D. D. Adrian, "A Review of Potentially Low Cost Sorbents for Heavy Metals,” Water Research, Vol. 33, 1999, pp. 2469-1479. doi:10.1016/S0043-1354(98)00475-8

[5] A. Saeed, W. Akhter and M. Iqbal, "Removal and Recovery of Heavy Metals from Aqueous Solution Using Papaya Wood as a New Biosorbent," Separation and Purification Technology, Vol. 45, No. 1, 2005, pp. 25-31. doi:10.1016/j.seppur.2005.02.004

[6] N. A. A. Babarinde, J. O. Babalola and R. A. Sanni, "Biosorption of Lead Ions from Aqueous Solution by Maize Leaf," International Journal of Physical Science, Vol. 1, No. 1, 2006, pp. 23-26.

[7] P. King, P. Srivinas, Y. P. Kumar and V. S. R. K. Prasad, "Sorption of Copper (II) Ion from Aqueous Solution by Teak Leaves Powder," Journal of the Hazardous Materials, Vol. B136, No. 3, 2006, pp. 560-566. doi:10.1016/j.jhazmat.2005.12.032

[8] M. A. K. H. Hanafiah, S. Shafiei, M. K. Harun and M. Z. A. Yahya, "Kinetic and Thermodynamic Study of $\mathrm{Cd}^{2+} \mathrm{Ad}-$ sorption onto Rubber Tree Leaf Powder," Materials Science Forum, Vol. 517, 2006, pp. 217-221. doi:10.4028/www.scientific.net/MSF.517.217

[9] M. A. K. H. Hanafiah, W. S. W. Ngah, S. C. Ibrahim, H. Zakria and W. A. H. W. Ilias, "Kinetic and Thermodynamic Study of $\mathrm{Pb}^{2+}$ Adsorption onto Rubber Tree Leaf Powder," Journal of Applied Science, Vol. 6, 2006, pp. 2762-2767. doi:10.3923/jas.2006.2762.2767
[10] M. A. K. H. Hanafiah, W. S. W. Ngah, H. Zakria and S. C. Ibrahim, "Batch Study of Liquid Phase Adsorption of Lead Ions Using Lalang Leaf Powder,” Journal of Biological Sciences, Vol. 7, No. 2, 2007, pp. 222-230. doi:10.3923/jbs.2007.222.230

[11] D. Karunasagar, M. V. B. Krishana, S. V. Rao and J. Arunachalam, "Removal of Preconcentration of Inorganic and Methyl Mercuary from Aqueous Media Using a Sorbent Prepared from the Plant Cariandrum sativum," Journal of Hazardous Materials, Vol. 118, No. 1-3, 2005, pp. 133-139. doi:10.1016/j.jhazmat.2004.10.021

[12] P. D. Johnson, M. A. Watson, J. Brown and I. A. Jefcoat, "Peanut Hull Pellets as a Single Use Sorbent for the Capture of Cu (II) from Waste Water," Water Mangement, Vol. 22, No. 5, 2002, pp. 471-780.

[13] S. Y. Quek, D. A. J. Wase and C. F. Forster, "The Use of Sago Waste for the Sorption of Lead and Copper," Water Research, Vol. 24, No. 3, 1998, pp. 251-256.

[14] Y. S. Ho, "Removal of Copper Ion from Aqueous Solution by Tree Fern,” Water Research, Vol. 37, No. 10, 2003, pp. 2223-2330. doi:10.1016/S0043-1354(03)00002-2

[15] A. K. Bhattacharya, S. N. Mandal and S. K. Das, “Adsorption of Zn (II) from Aqueous Solution by Using Different Adsorbents,” Chemical Engineering Journal, Vol. 123, No. 1-2, 2006, pp. 43-51. doi:10.1016/j.cej.2006.06.012

[16] A. Afkhami, M. Saber-Tehrani and H. Bagheri, "Simultaneous Removal of Heavy Metal Ions in Wastewater Samples Using Nano-Alumina Modified with 2,4-Dinitrophenylhydrazine,” Journal of Hazardous Materials, Vol. 181, No. 1-3, 2010, pp. 836-844. doi:10.1016/j.jhazmat.2010.05.089

[17] M. A. Tofighy and T. Mohammadi, “Adsorption of Divalent Heavy Metal Ions from Water Using Carbon Nanotube Sheets,” Journal of Hazardous Materials, Vol. 185, No. 1, 2011, pp. 140-147. doi:10.1016/j.jhazmat.2010.09.008

[18] J. Song, H. Oh, H. Kong and J. Jang, "Polyrhodanine Modified Anodic Aluminum Oxide Membrane for Heavy Metal Ions Removal,” Journal of Hazardous Materials, Vol. 187, No. 1-3, 2011, pp. 311-317. doi:10.1016/j.jhazmat.2011.01.026

[19] I. Gaballah, D. Goy, E. Allain, G. Kilbertus and J. Thauront, "Recovery of Copper through Decontamination of Synthetic Solutions Using Modified Barks,” Metellurgical Transactions B, Vol. 28, No. 1, 1997, pp. 13-23. doi:10.1007/s11663-997-0122-3

[20] A. Nakajima and T. Sakaguchi, "Recovery and Removal of Uranium by Using Plant Wastes,” Biomass, Vol. 21, No. 1, 1990, pp. 55-63. doi:10.1016/0144-4565(90)90047-N

[21] P. Lu and Y.-L. Hsieh, "Preparation and Characterirization of Cellulose Nanocrystals from Rice Straw," Carbohydrate Polymer, Vol. 87, No. 1, 2012, pp. 564-573.

[22] S. E. Abdel-Aal, Y. H. Gad and A. M. Dessouki, "Use of Rice Straw and Radiation-Modified Maize Starch/Acrylonitrile in the Treatment of Wastewater," Journal of Hazardous and Materials, Vol. 129, No. 1-3, 2006, pp. 204 215. doi:10.1016/j.jhazmat.2005.08.041 
[23] I. Vogel, "Elementary Practical Organic Chemistry, Part 3, 'Quantitative Organic analysis',” 2nd Edition, Longman Group Ltd., London, 1975, p. 652.

[24] S.-M. Xu, S. Feng, G. Peng, J.-D. Wang and A. Yushan, "Removal of $\mathrm{Pb}$ (II) by Crosslinked Amphoteric Starch Containing the Carboxymethyl Group,” Carbohydrate Polymers, Vol. 60, No. 3, 2005, pp. 301-305. doi:10.1016/j.carbpol.2005.01.018

[25] L. Gue, Z. Shu-Fen, J. B. Zhi and Y. J. Zong, "Study on Adsorption of $\mathrm{Cu}$ (II) by Water-Insoluble Starch Phosphate Carbamate," Carbohydrate Polymers, Vol. 63, No. 4, 2006, pp. 487-492. doi:10.1016/j.carbpol.2005.10.006

[26] D. K. Kweon, J. K. Choi, E. K. Kim and S. T. Lim, “Adsorption of Divalent Metal Ions by Succinylated and Oxidized Corn Starches,” Carbohydrate Polymers, Vol. 46, No. 2, 2001, pp. 171-177. doi:10.1016/S0144-8617(00)00300-3

[27] L. M. Zhang and D. Q. Chen, "An Investigation of Adsorption of Lead (II) and Copper (II) Ions by Water-In- soluble Starch Graft Copolymers," Colloids and Surfaces A: Physicochemical and Engineering Aspects, Vol. 205, No. 3, 2002, pp. 231-236. doi:10.1016/S0927-7757(02)00039-0

[28] R. Dhodapkar, N. N. Rao, S. P. Pande and S. N. Kaul, "Removal of Basic Dyes from Aqueous Medium Using a Novel Polymer: Jalshakti,” Bioresource Technology, Vol. 97, No. 7, 2006, pp. 877-885. doi:10.1016/j.biortech.2005.04.033

[29] M. I. Khalil and M. G. Abdel-Halim, "Preparation of Some Starch-Based Natural Chelating Agents,” Carbohydrate Research, Vol. 324, No. 3, 2000, pp. 189-199. doi:10.1016/S0008-6215(99)00290-6

[30] M. I. Khalil and S. Farag, "Utilization of Some Starch Derivatives in Heavy Metal Ions Removal," Journal of Applied Polymer Science, Vol. 69, No. 1, 1999, pp. 45-50. doi:10.1002/(SICI)1097-4628(19980705)69:1<45::AIDAPP6>3.0.CO;2-M 